\title{
The Stern Review on the Economics of Climate Change: contents, insights and assessment of the critical debate
}

\author{
O. Godard \\ Centre National de la Recherche Scientifique and Département Humanités et Sciences Sociales, Ecole \\ Polytechnique, PREG-X Econométrie, UMR 7176, 1 Rue Descartes, 75005 Paris, France
}

Received: 13 November 2007 - Revised: 4 February 2008 - Accepted: 14 February 2008 - Published: 20 February 2008

\begin{abstract}
Sir Nicholas Stern, former Chief economist of the World Bank, was asked by the British government to lead a review on the economics of global climate change. The Stern Review was published in October 2006 and attracted a great deal of attention from various circles, from academic to NGOs and the media in Europe, but also worldwide. This article aims first to highlight the Review's main points and to single out a selection of the most significant factual data and quantitative evaluations that make up the Review's rich contribution to the subject, going beyond the well-publicised striking results in which the possible damages of climate change are compared to the impact of the two world wars of the 20th century, but lasting forever. The survey concludes with reflections on criticism of the Stern Review made by several economists, mostly in the US, regarding the integrated assessment modelling exercise included in the Review. The most consequential criticisms are related to the low discount rate used to tackle this very long-term issue and the treatment of adaptation of future generations to a new global climate. Paradoxically, the much-attacked choice of a low discount rate chosen to ensure an equal treatment of the utility of all generations is the best-grounded in the utilitarian philosophy that underpins the type of economics that both the Stern Review and most of its critics share.
\end{abstract}

Keywords. Global climate change, integrated assessment, future studies, mitigation strategies, cost-benefit analysis, discounting, climate policies

\section{Table of Contents}

1 Introduction

2 General presentation

2.1 Contents of the review

2.2 A classical welfare economics approach enriched by concerns for intra and intergenerational ethics and economics of risk and uncertainty

2.3 Methodological features further explaining original results

3 Important messages

3.1 Major and lasting potential damage

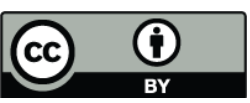

Correspondence to: O. Godard

(olivier.godard@shs.polytechnique.fr)
3.2 Disastrous climate change is in no way unavoidable and prevention is possible at a moderate cost

3.3 Other priorities to adopt and illusions to dispel

4 Some relevant data and insights

4.1 On GHG emissions and concentrations

4.2 The impacts of climate change

4.3 Policies to combat climate change

5 Two additional comments on climate policies

6 An assessment of the critical debate triggered by the Stern Review

6.1 A mixed reception

6.2 Three main lines of economic criticisms

6.3 The key role of the social discount rate

6.4 An ambiguous adaptation

7 Conclusion

Published by Copernicus Publications on behalf of the Institut Veolia Environnement. 


\section{Introduction}

The Review of Economics on Climate Change was prepared under the responsibility of Sir Nicholas Stern, Head of the British Government Economics Service and Adviser to the British Government on the economics of climate change at the request of the Chancellor of the Exchequer, the Rt. Hon. Gordon Brown. Launched in autumn 2005, the review was drafted by an ad hoc team of some twenty experts, climatologists and economists working under the steering of Sir Nicholas Stern. Various research centres were asked to submit a set of specialised theme studies. A consultation procedure which included a call for contributions was also set up. The report was finally published on 30 October 2006.

Since its publication, the Stern Review has given rise to much comment and a number of statements. It came under criticism from economists and a few climatologists. Between November 2006 and February 2007, the Stern Review team sought to clarify points that had been found obscure or misleading and also to refute criticisms that they considered to be unfounded. As a result a number of supplementary documents were prepared, including in particular three summaries of reflections and responses that were put on line on 12 February 2007. As was to be expected, the authors of the report accepted that certain technical points could have been broached differently, but despite criticism, maintain that their approach is justified, that it is scientifically and ethically well founded and that their conclusions are robust.

The present article is assigned two goals. First, it is intended to present the main points made in the report and the body of information, factual data and quantitative evaluations which form the Review's substantial contribution to the subject, supplementing the main results and principal recommendations which it arrives at. This presentation is based essentially on the report itself but also takes account of additional contributions (see the list in Box 1). To this regard, the paper does not aim to introduce a critical discussion of specific data or statements included in the Review, which is already a referenced review of scientific literature. Secondly, since the Stern Review triggered a significant critical debate, it is no more the appropriate time to produce just another critique of the Stern Review itself. Meanwhile, it has been deemed useful to give an aperçu of the debate on key framing points and to enter in a critical examination of this debate. Not all economists, especially in the USA, have been sympathetic with the methodological choices and the results delivered by the Stern Review. Are these criticisms as convincing as their authors would wish?
- N. Stern (dir.) (2006) The Stern Review Report: the Economics of Climate Change, London, HM Treasury, October 30, 603 pp.

- N. Stern (dir.) (2006) Postscript to the Stern Review Report, December, 7 pp.

- N. Stern (dir.) (2006) Technical Annex to Postscript, December, 13 pp.

- N. Stern (dir.) (2007) Response to key themes in recent critiques of the Stern Review, January, 2 pp.

- N. Stern (dir.) (2007) Stern Review - Frequently asked questions, January, $10 \mathrm{pp}$

- N. Stern (dir.) (2007) After the Stern Review: reflections and responses, 12 February:

- Paper A: "The case for action to reduce the risks of climate change", $50 \mathrm{pp}$.

- Paper B: "Value judgements, welfare weights and discounting: issues and evidence", $18 \mathrm{pp}$.

- Paper C: "Building an effective international response to climate change", $32 \mathrm{pp}$.

These documents are available on the internet at: www.hm-treasury. gov.uk/independent_reviews/stern_review_economics_climate_change/ sternreview_index.cfm. In the following references to the core report are indexed as "SR".

Box 1: Reference documents published by the Stern Review team.

\section{General presentation}

\subsection{Contents of the review}

The report, totalling almost 600 pages, resembles in perspective and presentation reports by the Intergovernmental Panel on Climate Change (IPCC); it adopts a global perspective and is based on salient points observed in a broad subjectby-subject review of international scientific literature. It does however reveal a greater degree of freedom as regards the selection of sources and the normative choices on which the proposed evaluation is based, in particular as regards ethical standpoints. Unlike the IPCC reports the Stern Review was not submitted to an extensive international peer-review process. Its status is that of a report prepared over a period of one year by a single team at the behest of a government. That being said, the report also mentions sectoral studies specially commissioned for the purpose. The Stern Review team itself produced original simulation and evaluation work, using a pre-existing model, PAGE2002 (Hope, 2006), to produce a set of scenarios and values on climate change and resulting damage.

As a result of the above process, the contents of the report are somewhat hybrid: the variety of source data in combination with the use of a single model prevents the exercise from being totally coherent. Methodological simplifications and somewhat arbitrary choices were introduced which can of course be disputed. Combining normative choices grounded on ethics and approaching the impact on economic agents' welfare on the basis of market data supposed to express relevant utility aspects through the willingness to pay of those presently living agents also leads to some gaps and discrepancies: due to cognitive biases and psycho-sociological 
obstacles (Dupuy and Grinbaum, 2005; Bazerman, 2006), interpreting observed markets as expression of relevant preferences just reproduces an irrational way to consider the issue of climate change.

The subject matter ranges from identification of the various categories of climatic impact to disaggregated evaluation of the damages, then their aggregated evaluation in a monetary framework, with finally an evaluation of the political response strategies. The report therefore contains six sections. The first one (SR, p. 1-54) reports on recent climate data and defines the framework of the economic evaluation exercise. The second one (SR, p. 55-167) makes an inventory of data on impacts and includes them in an integrated evaluation model to arrive at an evaluation of damages. The third one (SR, p. 168-307) deals with the economics of stabilisation of atmospheric concentrations of greenhouse gases (emission paths depending on various targeted concentration levels, cost calculations, competitiveness issues, comparison of costs and benefits). The fourth one (SR, p. 308-402) studies mitigation policies based on a reduction of net greenhouse gas (GHG) emission levels. The fifth section (SR, p. 403448) deals with economic adaptation policies of individuals and economies to the portion of climate change which will still be taking place despite the level of prevention adopted. The sixth and last section (SR, p. 449-475) broaches the issue of international action.

\subsection{A classical welfare economics approach enriched by concerns for intra and intergenerational ethics and economics of risk and uncertainty}

The essential options chosen to structure the evaluation reside, albeit with caution, in the tradition of orthodox welfare economics which the report handles with sophistication: a consequentialist and utilitarian approach to evaluate the damages; a comparison between the cost of damages and the cost of prevention and adaptation to determine a range of desirable policies; a proposal to ensure a satisfying emission pathways over 200 years (until 2200) using the probabilistic approach of climatic risk, moderated however by numerous warnings that models have their limits and are only indicative.

Despite the constraints imposed by the purpose of a review, the Stern report contains some new and original aspects compared to work previously published by IPCC. Originality resides in some cases in the approach itself; in others it is due to a marshalling of results which were more recent than those used by IPCC in its 2001 report (see Box 3 for a short account of results of 2007 report of IPCC WG 1).

The approach displays originality on three counts:

1. It underlines the dimensions of the risk and the uncertainty regarding climate damages, taking account of what economists designate as "risk and ambiguity aversion", instead of confining itself to standard mean val- ues; the main body of risk accounting is done by calculating probabilities and adopting risk aversion coefficients. Uncertainty proper, remaining outside probabilistic assessment, is taken into account either indirectly by giving sustained attention to "extreme" possibilities identified in the literature, or by qualitative pronouncements added to probabilistic quantitative evaluations and underlining the need to prepare for higher damage values than those which would result from these secured quantitative evaluations.

2. It introduces correction factors for gross loss of welfare values to take into account the considerable income inequalities between countries affected by climatic impacts (industrialised, emerging and developing countries); these correction factors give a higher value to the welfare effect of a monetary damage unit when victims have a lower income. The coefficient elasticity equals 1. In the context of the utility function adopted, this means that gross damage of one euro suffered by someone whose income is 100 has a weight which is ten times greater than a damage of the same worth affecting someone whose income is 1000 ; or that an action which would reduce marginally the rich man's income by 10 , but would improve the poor man's by at least 1 , would improve collective welfare.

3. It adopts a normative framework giving the same welfare weight (utility) to all generations to appear until 2200 , except for a small coefficient representing the probability of mankind's disappearance (due for example to a large meteorite colliding with the planet); in technical terms, the utility of the successive generations is almost left untouched by discounting. The main reason for discounting in the Stern Review is therefore not time, but the expected increase in future wealth per capita due to economic growth. This produces a low discount rate (central rate is $1.4 \%$ ) reflecting essentially the expectation of increased consumption (in a general sense) per capita in the long term (1.3\%). Getting an aggregate assessment of impacts of climate change implies a means
to compare and weigh damages experienced at different dates from now to the
distant future. The ratio between the value of an extra damage unit at some fu-
ture date and the present value given to this same unit of damage is called the
discount factor. The way the value of this discount factor is increasing with time
is called the discount rate. Formally, the discount rate is analogous to an interest
rate on the capital market. From a standard economic perspective, the practice of
discounting embraces two components: first an observation that individuals gen-
erally have a preference for the present, which means that they prefer consuming
a good today than tomorrow, and tomorrow instead of the day after tomorrow,
and so on -impatience-; this is supposed to be a key variable underpinning sav-
ings behaviors and explaining why borrowers have to pay an interest; second,
because of economic growth allowed by investment, there is a presumption that
people will get richer in the future than today; hence, the utility derived from one
additional unit of consumption decreases when people become richer. Earning
one more dollar when you already have $\$ 1$ Million is less attractive than if you
have only $\$ 100$. Consequently, the standard formula used in social cost-benefit
analysis is the following: $r=\delta+\eta g$ with $r$ the social discount rate, $\delta$ the pure time
preference rate, $\eta$ the elasticity of marginal utility of per capita consumption, and
$g$ the per capita consumption growth rate.

Box 2: Discounting future damages. 


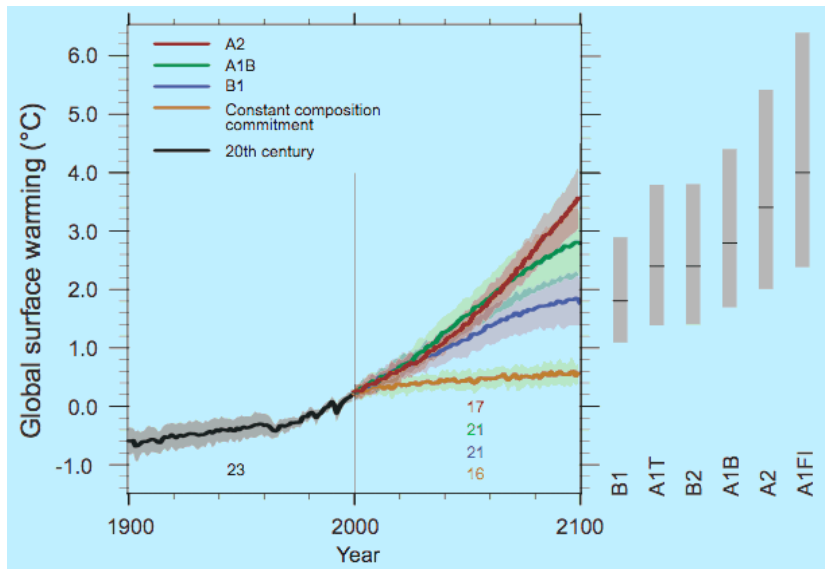

Figure 1. Incidence of various development scenarios on global average temperature (base of comparison: 2000 temperature). This figure shows expected temperature increases in some IPCC scenarios. The reference year is 2000 , not pre-industrial levels, that are $0.7^{\circ} \mathrm{C}$ lower. The number of modelling runs for a given time period and scenario is indicated by the coloured numbers at the bottom part of the panel. The orange line represents a benchmark hypothetical scenario where concentrations are held constant at year 2000 values. Other lines represent IPCC scenarios. The gray bars at right indicate the best estimate (solid line within each bar) and the likely range assessed for six basic IPCC scenarios. Extract from Summary for Policymakers - WG1-IPCC, February 2007, p. 21.

The Stern Review therefore uses a framework of assumptions which, although not entirely new and explicitly grounded in well-established economic and ethical reflection, are nevertheless rather original compared to those which govern a significant portion of the work of economists on climate change, in particular in respect of the discount rate, which appeared to be one of the major points of dissent. The Stern Review considers that the problem under study (a global very long term issue) is such that there must be a break with the traditional practices used by public administration for project analysis, which are only settled for a rather short time period comparing with the two centuries chosen by the Stern Review. Based on both ethics and long term growth assumptions, the rate is designed to balance the conflicting demands of attitudes to risk and value judgements on distributive justice (the greater the inclination to redistributing wealth from rich to poor, the higher the rate since future generations are supposed to be richer, on the mean, than present ones) and inter-generational ethics (the greater the concern for the interests of future generations, the lower the rate). I come back to the discussion of discounting in Sect. 6.3.

\subsection{Methodological features further explaining original results}

The conclusions of the Review are also rather original because of three further features:
1. It uses a model belonging to a climato-economic family developed in the last fifteen years called Integrated Assessment Models (IAMs) which integrate into the same model the relationships between economic development pathways, GHG emissions, atmospheric concentrations of GHGs, climatic changes and their various impacts, essentially productive and commercial impacts (loss of agricultural production, loss of natural resources, loss of real estate and infrastructure, impact on energy consumption). When valuing these impacts, the Stern Review also considered the environmental and health repercussions (morbidity and mortality, loss of ecosystems and species extinction) as such and the contingent indirect effects (investment depression, migrations, conflicts and political instability), beyond loss in output and income.

2. It takes into account the most recent studies on climatology considering various possibilities of positive feedback loops amplifying climate disequilibrium (weakening of plant and ocean carbon sinks, methane emission from thawing frozen ground, ocean hydrates methane emissions, etc.). As a result the Stern Review attaches greater importance to the possibility of diverging to new and more unstable climatic regimes for which long term values would tend towards the higher values of key parameters. Generally speaking, the assessment of incidence on the mean global temperature for a given level of atmospheric GHG concentration is higher than in previous IPCC reports and also than in the IPCC Working Group I Fourth Assessment Report (2007) (see Box 3 and Fig. 1).

Furthermore, the studies used by the Stern Review team now formulate probabilities on proposed values. For a $550 \mathrm{ppm} \mathrm{CO}_{2} \mathrm{e}\left(\mathrm{CO}_{2}\right.$ emissions plus other GHGs converted as a function of their warming potential index in 100 years - see Box 4 for a definition of ppm) the increase of average temperature values proposed by a battery of models range from $1.5^{\circ}$ to $4.5^{\circ}$ Celsius for a confidence interval of $95 \%$ probability, with a central value of $3^{\circ}$, whereas this concentration level was long associated with an increase of only $2^{\circ}$, for example for the objectives adopted by the European Commission. According to data used in the Stern Review, the central concentration value which could be expected to limit the temperature rise to $2^{\circ} \mathrm{C}$ is $450 \mathrm{ppm}$ of $\mathrm{CO}_{2} \mathrm{e}$, leaving approximately $390 \mathrm{ppm}$ for $\mathrm{CO}_{2}$ alone (see Fig. $2^{1}$ ). These figures have been confirmed by the 2007 IPCC Fourth Assessment Report: compare Figs. 2 and 3 thereafter.

\footnotetext{
${ }^{1}$ Since IPCC reports are based on published literature and submitted to dual reviews by peers and scientists representing governments from all regions of the globe with diverse and even sometimes conflicting interests, these reports must be considered as representing a minima formulations.
} 


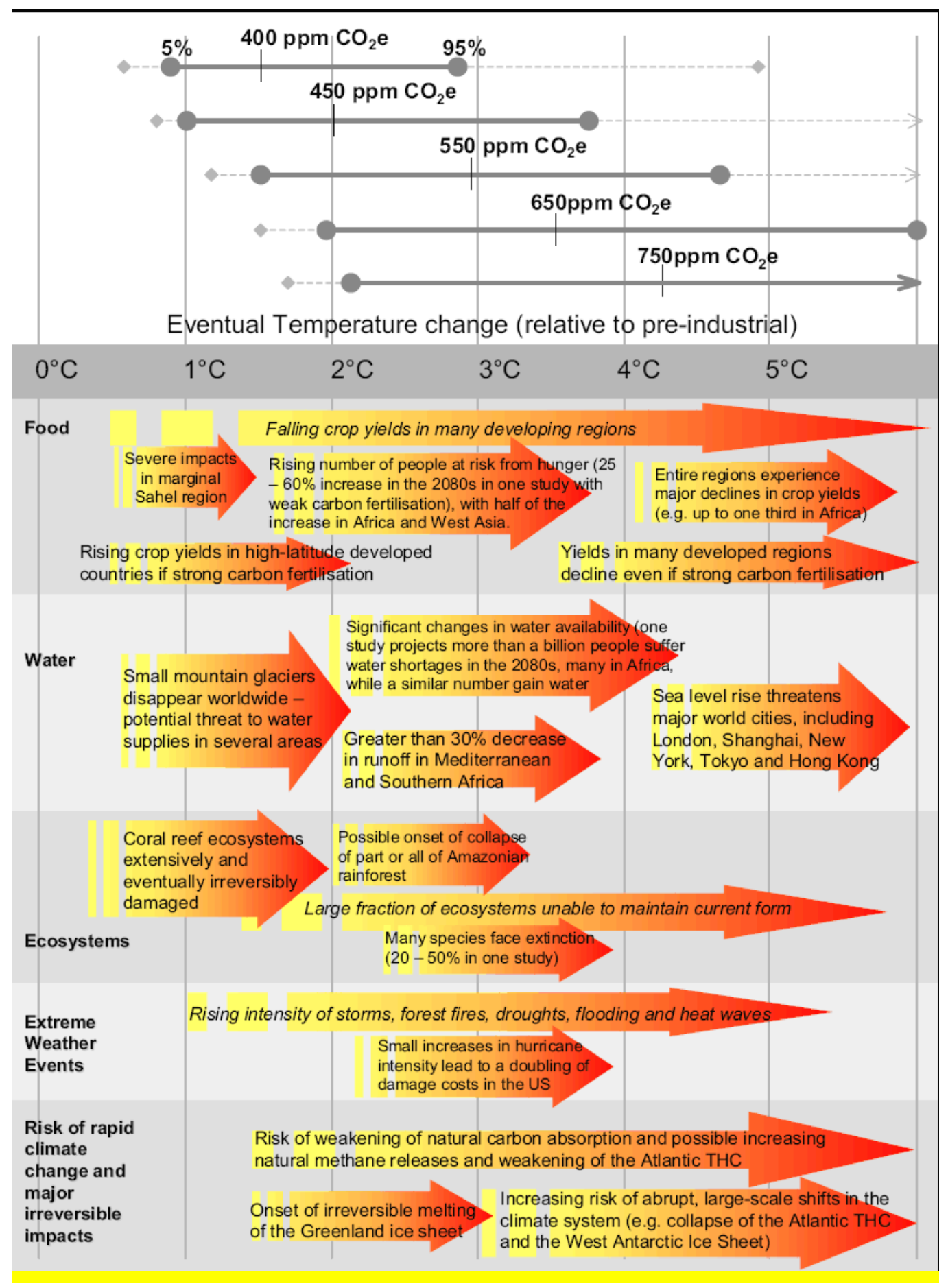

Figure 2. Stabilisation levels and probability ranges for temperature increases. The top panel shows the range of temperatures projected at stabilisation of concentration levels between $400 \mathrm{ppm}$ and $750 \mathrm{ppm} \mathrm{CO}_{2} \mathrm{e}$ at long run equilibrium. The solid horizontal lines indicate the $5-95 \%$ probability range based on climate sensitivity estimates from the IPCC 2001 and a recent Hadley Centre overall study. The vertical stroke indicates the mean of the 50th percentile point. The dashed horizontal lines show the 5-95\% range based on eleven recent studies. The bottom panel illustrates the range of impacts expected at different levels of warming. From Fig. 13.4 (SR, p. 294). 


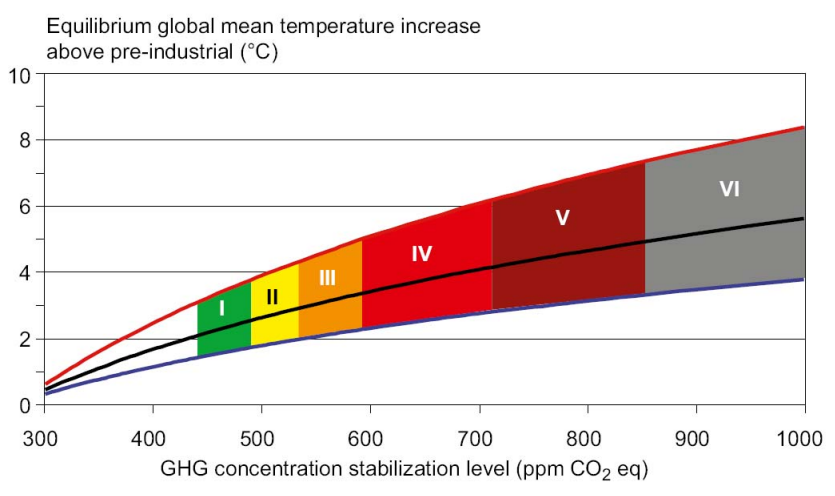

Figure 3. Global mean temperature increase as a function of GHG concentration level. The middle, black line represents the "best estimate" of climate sensitivity of $3^{\circ} \mathrm{C}$. Climate sensitivity is defined as the global mean equilibrium temperature induced by a doubling of $\mathrm{CO}_{2}$ atmospheric concentration. The coloured bands reflect various stabilization scenarios designed for different targets. Extract from p. 42 of Technical Summary of IPCC WGIII Fourth assessment Report (2007).

3. It uses a specific non-linear function to represent the relationship between temperature increases and the intensity of effects and damage. In support of that process, the Stern Review quotes some empirical data. For example, in certain regions, an increase in average temperature of 1 degree can multiply by 10 the frequency of extreme heat waves; an applied modelling run produced by William Nordhaus (2006) for hurricanes shows that an increase of 5 to $10 \%$ of the intensity of this type of event can lead to doubling damage. For instance Hurricane Katrina alone, in 2005, caused total economic damage estimated by Munich Re at $\$ 125 \mathrm{bn}$, representing $1.2 \%$ of US GDP for one year, of which only half was insured (SR, p. 132).

\footnotetext{
The Summary indicates in particular that positive feedback which could amplify climate change has not been included in the assessment of future evolution of mean global warming or rising sea levels values because of scientific uncertainty on the subject.

It states that global surface temperatures have risen by $0.70^{\circ} \mathrm{C}$ during the 20th century $(0.76$ since 1850$)$ and that additional temperature increases in the course of the 21 st century could range between 1.8 and $3.9^{\circ} \mathrm{C}$ in median values depending on the scenarios studied, which is a spread of total median values between 2.5 and $4.6^{\circ} \mathrm{C}$ compared to the beginning of the industrial age. Considering the whole range of values for each IPCC scenario, the results are values situated between the two extremes of 1.8 and $7.1^{\circ} \mathrm{C}$, compared to the same pre-industrial values. The breadth of the range reflects mainly two components: scientific uncertainties on the one hand, and historical uncertainties on human development paths during the present century and the ensuing GHG emission paths on the other hand.

Although a certain level of climate change seems inevitable, its magnitude will depend to a considerable degree on human activity in the next decades.
}

Box 3: IPCC Working Group I Fourth Assessment Report,

Summary for Policymakers (2 February 2007). ppm (parts per million) is the ratio of the number of GHG molecules to the total number of molecules of dry air. $1 \mathrm{ppm}$ equals one millionth. The atmospheric concentration of the $6 \mathrm{GHGs}$ considered by the Kyoto Protocol ranges from 280 (preindustrial value) to 380 (present value) for $\mathrm{CO}_{2}$ and 430 for all Kyoto GHGs. In the future, by 2100 , figures are expected to be between 450 (quasi-stabilization at present global values) if policies are very proactive and implemented immediately, and 1000 with a business-as-usual (BAU) scenario. Over the last decade, the annual $\mathrm{CO}_{2}$ concentration growth was $1.9 \mathrm{ppm}$. 1 extra ppm corresponds to emissions of 15 to $20 \mathrm{GtCO}_{2}$. The present level of concentration of GHGs is without precedent in the last 650,000 years (IPCC, 2007:2) and presumably still more

Box 4: What ppm are.

\section{Important messages}

In this ambitious assessment report several striking messages stand out and a few catch phrases have caught the public eye.

\subsection{Major and lasting potential damage}

As regards physical impacts, a doubling of the pre-industrial concentration of GHG $(280 \mathrm{ppm})$, i.e. around $550 \mathrm{ppm}$, which would be reached between 2030 and 2060, would probably imply a mean long run equilibrium temperature increase, compared to pre-industrial values, within a 2 to $5^{\circ} \mathrm{C}$ range. At that level of GHG concentration, there would be a $20 \%$ chance that average temperature would be in excess of $5^{\circ}$. A $5^{\circ}$ rise in temperature would be without precedent in all the history of mankind and corresponds to the same kind of difference as between the present situation and the last ice age.

Such a change would inflict physical damage on the natural environment, human life and health, but would also have an effect on the various components of productive capital, leading to a significant impact on the possibility of economic growth. The negative effect on investment could, in cumulative incidence, at least double the level of direct damage measured in loss of consumption per inhabitant of traded and non-traded goods and services. In order to reduce the vulnerability of the poorest countries and facilitate their adaptation, the Stern Review advocates urgent fostering of their growth and development.

When all types of damage are aggregated, climate change would involve a serious and lasting loss of consumption and wellbeing. If all the temporal, geographic and social differentials are eliminated in order to produce a simple "smoothed" representation, like an annuity in a set of heterogeneous financial flows, all of the climate changes would be equivalent, in wellbeing, of an annual and irreversible permanent rate of loss of an increasing global per capita consumption. According to the degree of integration of various categories of phenomena, this permanent rate of loss could be in the 5\%-20\% range. If only gross productive and trade impacts are measured, they total $5 \%$. Taking into account the incidence on human health (induced mortality) and environmental losses (rapid erosion of biodiversity), the cost rises to $11 \%$. Taking on board the risks of overresponse of the climate to concentrations (amplifying feedback) the result is $14 \%$. Finally, 
since damage would be concentrated in the poorest areas and by taking account of indirect contingent effects, economic, demographic and political (migrations, conflicts) ones in particular, the figure would approach $20 \%$.

The examples given to present these results reflect the figures: mankind would be confronted with lasting damages equivalent to those brought on by the economic crisis of 1929 or the two world wars in the 20th century.

This first presentation of the conclusions of the Stern Review should not be downsized but supplemented by considering a set of additional factors and features.

Some scientists have put forward the assumption that a very moderate climate change could have positive effects for economic development, at least in certain parts of the world (Siberia, etc.). The Stern Review does not exclude that theory but remarks that recent literature reduces its scope. The "positive" estimates (availability of new areas for agriculture, increases in agricultural and forestry productivity) were the result of theoretical models that led to an overestimate of the favourable influence of carbon fertilisation intensity on agricultural yields. Full scale experiments and consideration of other limiting factors have recently produced values reducing by half the initial theoretical evaluations ${ }^{2}$ and at the same time have noted inversion phenomena which appeared as soon as temperatures rose significantly, i.e., when temperature increase stands higher than a current range of variation, productivity of existing biomass is decreasing because environmental conditions depart from the biological optimum.

Another point is that various types of damage would not only have a single effect but would also interact with each other. This compounding of impacts can considerably amplify the economic effects and the global impact on welfare: water cycle disruption, health aspects, reduced agricultural production and repetitive extreme events could all combine to become serious obstacles to development, in particular by overwhelming the capacity for adaptation which could a priori be available in the case of partial and limited stress.

Damages will mainly be felt in the long term, beginning after 2050 and with more intensity after 2100 particularly, but will then become very long-lasting ${ }^{3}$. The differences in damages measured as a percentage of a Gross World Product (GWP), itself progressing with time, would be 1 to 4 between 2060 and 2100, 1 to 25 between 2060 and 2200 for the more severe scenario (high climate sensitivity, extreme events, non-market-impacts) (see Fig. 4). Climate is a very long term problem with roots in the past and present and involves a major time lag between the moment when something happens (GHG emissions) and the moment when the

\footnotetext{
${ }^{2}$ This downward readjustment seems to be ignored by some critiques of the Stern Review.

${ }^{3}$ According to calculations made by Yohe (2006), with the pure preference rate for the present chosen by the Stern Review Team $(0.1 \%)$, damages posterior to 2200 should double the total damage attributed to climate change until 2200.
}

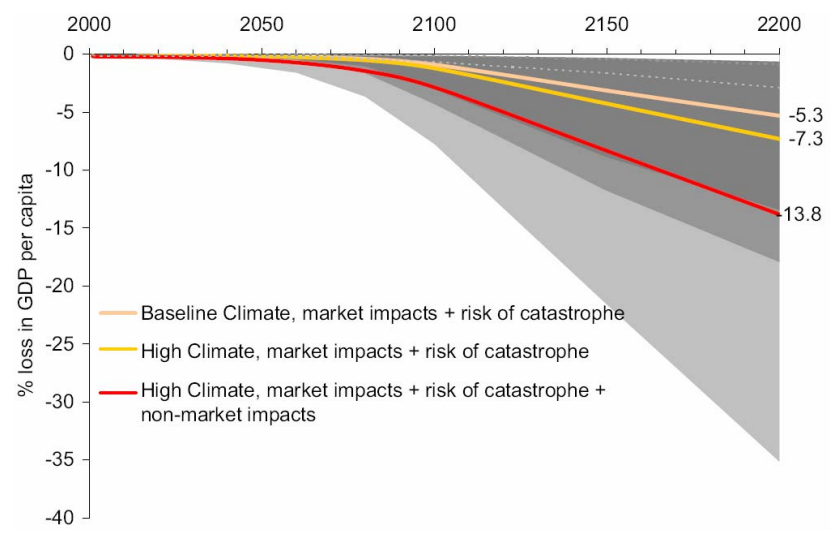

Figure 4. The impacts of climate change. Extract from Fig. 6.5d, (SR, p. 157): the shaded surface indicates the values for a $5-95 \%$ range of probability.

effects are registered. People living in industrialised countries and indifferent to the fate of humankind after 2050 do not really need to worry overmuch about climate change.

Damages will be very unevenly distributed over the planet: the rise in temperature will be felt faster and much more strongly over land than over oceans, at higher latitudes than in the tropics; existing geographic disparities in rainfall distribution will be accentuated, the sub-tropical areas will be the worst hit by drought (Mediterranean-Sahel zone, South Africa) as will South-East Asia; with a $2^{\circ}$ rise in temperature, these sub-tropical areas could lose as much as $30 \%$ in rainfall volumes (Table 3.1, SR, p. 57). In total, damage estimated for Africa, the Middle East, India and South-East Asia would total more than twice the mean global GDP loss percentage in 2100 (SR, p. 158).

Depending on the temperature level reached, uncertainty is growing as regards the spectrum of possible physical, environmental, economic and social events: we know rather little about the way in which the world would live at $4^{\circ} \mathrm{C}$ higher than the present level, to say nothing of the case of a temperature increase greater than $10^{\circ} \mathrm{C}$. That is the reason why the economics of risk and uncertainty are such a pivotal part of the evaluation proposed by the Stern Review.

\subsection{Disastrous climate change is in no way unavoidable and prevention is possible at a moderate cost}

Despite the very alarming picture of possible damages and daunting surprises which would arise from climate change, global disaster is in no way inevitable. An international policy to control the climate problem is technically and economically possible. It does however depend on whether the international community adopts the appropriate objectives and on how fast strong policies can be implemented. In line with a long term stabilisation objective of $550 \mathrm{ppm} \mathrm{CO}_{2} \mathrm{e}$ concentrations, which appears to be the long term target that should 


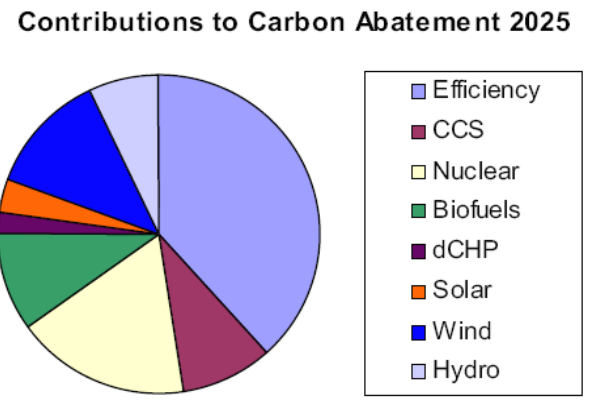

Abatement $11 \mathrm{GtCO} 2$

Contributions to Carbon Abatement, 2050

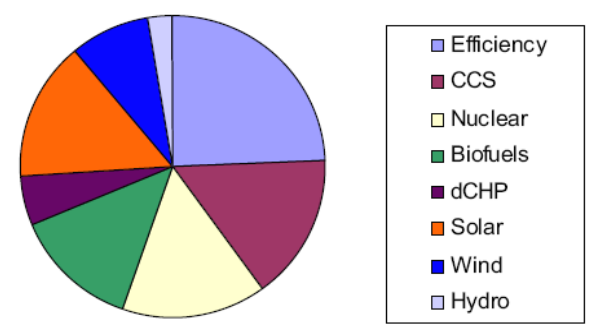

Abatement $43 \mathrm{GtCO} 2$

Figure 5. The distribution of emission savings by technological advance by 2025 (SR, p. 230). CCS is for Carbon Capture and Sequestration; DCHP is for Decentralised power generation, including micro-generation, combined Heat and Power.

not be transgressed according to the Stern Review, a level of global emissions by $205025 \%$ below current levels would be achievable for a not insignificant but still affordable annual cost estimated as contained in the range of $-3 \%$ (positive impact on growth) to $+3 \%$ of GWP (pessimistic scenario ignoring all the cost-lowering factors of existing techniques and already advantageous opportunities) ${ }^{4}$. The Stern Review adopts a central value of $+1 \%$ of GWP, i.e. a cost approximating $\$ 1000$ bn by 2050 . At that level of concentration $\left(550 \mathrm{ppm} \mathrm{CO}_{2} \mathrm{e}\right)$, the cost of residual climate damages would be equivalent to an annual and irreversible loss of $1.1 \%$ of consumption per head. This means that the total cost of climate change (cost of damages and cost of prevention) would be equivalent to a little over $2 \%$ of consumption per head, now and forever after.

Keeping prevention costs reasonably low depends on several factors:

- that action be implemented by most countries representing the largest share of GHG emissions;

- that strong policies be implemented without delay, in particular those which have an impact on technical innovation, so that emission pathways could begin to fall

\footnotetext{
${ }^{4}$ The baseline scenario would lead to a doubling of GHGs emissions between 2030 and 2060.
}

Table 1. The main sources of gain from prevention costs. Metaanalysis estimates: average impact of model assumptions on World Gross Product in 2030 for stabilisation at 450 ppm $\mathrm{CO}_{2}$ (approximately $500-550 \mathrm{ppm} \mathrm{CO}_{2} \mathrm{e}$ ). The baseline outcome results from worst case assumptions. On top of this, the analysis considers additional assumptions that mitigate the worst case assumptions. Their effects are supposed to be additive. Taking account of all extraassumptions, adding their effects on the worst case, leads to the best case estimate: the loss of output associated with the worst case is possibly substituted by a gain of output in the best case ( $\%$ point levels difference from base model run).

\begin{tabular}{lr}
\hline Worst case assumptions & -3.4 \\
Sources of gain Active revenue recycling & 1.9 \\
CGE model & 1.5 \\
Induced technology & 1.3 \\
Non-climate benefit & 1.0 \\
International mechanisms & 0.7 \\
"Backstop" technology & 0.6 \\
Climate benefit & 0.2 \\
Total extra assumptions on sources of gain & 7.3 \\
Best-case assumptions & +3.9 \\
\hline
\end{tabular}

Source: Table 10.1 (SR p. 243, extracted from Barker et al., 2006)

significantly by the next $10-20$ years. Peak emissions worldwide should be reached by 2020 at the latest and net total emissions should then begin to diminish at an annual rate of 1 to $3 \%$. Any delay in implementing policies would lead not only to rapidly dwindling chances of achieving the goal, and therefore greater threats to world climate, but also to being forced into taking subsequently more drastic and costly action within a shorter time. For instance, deferring peak global emissions from 2020 to 2030 would mean accelerating twofold the later rate of decline of emissions required to reach stabilisation at $550 \mathrm{ppm}$ of $\mathrm{CO}_{2} \mathrm{e}$.

- that policies be adopted which use, as required, the entire range of instruments for action so as to affect all sectors, but giving priority to instruments which assign a price to GHG emissions. The idea would be to combine firm overall commitment to quantitative goals with flexibility in sectoral and local implementation of policies so as to minimise cost. Particular attention should be given to the choice of efficient strategies for recycling the revenues of carbon taxes or auctioned tradable permits. The Stern Review pleads in favour of a two-pronged approach: achieving a global carbon price through quota trading or taxation so as to coordinate the whole process of adjustment efficiently and implementing a policy to foster technical progress and innovation (R\&D programmes, technical cooperation, technology transfers, technical progress induced by price signals). The challenge is such that only a combination of these 
two strategies could rise to the occasion. See Fig. 5, possible distribution of reductions to be obtained by technology. Technological advances are expected to halve the mean cost of abatement by 2025 . See also Table 1 for the main macro-economic components of gains to be expected through specific directions of cost-abating policy measures, assessed as a percentage of GDP.

Table 1 highlights the key role played, as regards costs, by four variables: recycling strategies for the tax revenues from policy instruments, induced technological progress, ancillary environmental benefits (excluding climate change) as a result, for example, of reduced impacts on health due to car pollution and coal-fuelled urban heating, and the existence of international flexibility mechanisms.

Altogether, economic growth and development would be more jeopardised by a business-as-usual (BAU) policy ignoring the climatic threat than by a policy for the control of the climate risk with long term stabilisation within the 450550 ppm of $\mathrm{CO}_{2} \mathrm{e}$ range - which for $\mathrm{CO}_{2}$ alone represents a bracket of 390-500 ppm - as its objective.

\subsection{Other priorities to adopt and illusions to dispel}

In the short term, taking into account the high inertia of energy systems due to the long life of equipment and infrastructures, an essential point is to prevent new investments from confining mankind in high carbon emission profile technologies for several more decades. The development pattern of emerging countries is of course a prime concern, with the issue of coal-fuelled power stations. If new investments in energy production, not forgetting infrastructures and buildings, were to be an occasion for adopting low-profile $\mathrm{CO}_{2}$ technologies, an annual gain of $6 \mathrm{GtCO}_{2} \mathrm{e}$ could be obtained by 2030 at practically no extra cost!

Policies to be implemented must beware of two pitfalls: on the one hand unrealistic determination regarding objectives; on the other, deferring any significant action until happier technological circumstances prevail.

In fact, setting a mandatory objective, with no leeway, for long term stabilisation of GHG concentration at $450 \mathrm{ppm}$ of $\mathrm{CO}_{2} \mathrm{e}$, would probably be very costly since it would signify managing after a very early peak, by 2010 , to reduce emissions by $7 \%$ a year, so as to arrive at emissions two thirds lower than current levels by 2050 (SR, p. 201). Nevertheless, that is the objective which would be required as a central value to avoid a long term rise in temperature of over $2^{\circ} \mathrm{C}$. The rate of reduction would be halved if the pathway was allowed to reach a $500 \mathrm{ppm}$ level at one point on the way to long term stabilisation at $450 \mathrm{ppm}$. But this would imply that for over a century, temperatures and risks would be those associated with the $500 \mathrm{ppm}$ level. For temperatures, that would be $0.5^{\circ} \mathrm{C}$ more between 2030 and 2150 for the same final stabilisation goal.
It would however be totally unrealistic to wait for major technology breakthroughs to start implementing strong policies for emission control: the problem will be solved through multiple innovations, many of them incremental, and by changed life-styles and economic incentives. The time limits for mitigation policies to be relevant means mankind cannot afford to wait several decades for hypothetical major technological breakthroughs to come on stream.

It would be just as unrealistic to pin one's hopes on the notion that our descendants will manage to adapt fully to the new climate situation: business-as-usual would lead to temperature levels and biophysical disturbances of such magnitude that the process of adaptation, which will be necessary anyway regardless of the climate control strategy adopted, could not obviate considerable and irreversible damages. In other words, transferring the whole burden of compulsory adaptation to future generations is ethically unacceptable (see the discussion in Sect. 6).

One final illusion would be to consider that a project approach (similar to the JI/CDM in the Kyoto Protocol) would be sufficient for all countries worldwide to join forces in the fight against climate change. This approach is not adequate for the purpose and would not be sufficient to put humankind as a whole on the right path. The world needs overall management of large financial flows connected to the carbon constraint aimed at developing and emerging countries ${ }^{5}$. In this framework, which remains to be developed, specific mechanisms could be found for certain countries or sectors. For example, the Clean Development Mechanism (CDM) could be extended to policies, programmes and projects in the least developed countries; border adjustment mechanisms could be implemented for interim periods in countries which, having adopted ambitious quantified objectives for reducing emissions in sectors such as cement and aluminium, are exposed to asymmetric competition from manufacturers not subject to such constraints.

\section{Some relevant data and insights}

The Stern Review contains a large amount of more or less specific information and data selected from worldwide scientific literature. This is a key element giving this report its value. Some are listed below.

\subsection{On GHG emissions and concentrations}

In 2000, GHG emissions were attributable to energy for $65 \%$ and to non-energy sources for 35\% (see Fig. 6 from WRI, 2006). Energy sources have displayed the highest

${ }^{5}$ If developed countries accepted a goal of $90 \%$ abatement of GHGs by 2050 on 1990 levels and achieve $50 \%$ of the needed investment by helping LDCs to control their own emissions, it would involve annual financial flows of investment of $\$ 40$ Billion to the latter (SR, p. 460). 


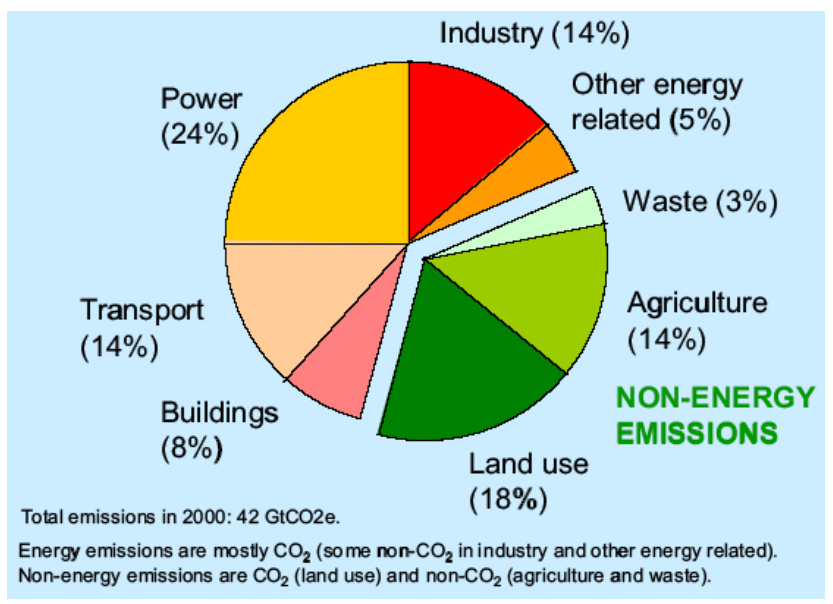

Figure 6. GHG emissions per source in 2000 (from SR, p. 171).

growth rates: $+3 \%$ annually for energy-related $\mathrm{CO}_{2}$ during the 1950-2002 period, with a lower rate since the eighties. Between 1990 and 2000, the average annual rate of growth of non- $\mathrm{CO}_{2}$ GHGs was $0.5 \%$ and of all GHGs together $1.2 \%$ (SR, p. 175). These differences are likely to persist in the future.

The average annual increase in atmospheric concentration of the 6 GHGs considered by the Kyoto protocol since 1980 is around 2-3 ppm and the mean temperature rise has been $0.2^{\circ} \mathrm{C}$ per decade. But this is accelerating: in 2000 , the annual increase was $2.7 \mathrm{ppm}$ (SR, p. 169). With a BAU scenario, the annual rate would be $4.5 \mathrm{ppm}$ by 2035 . If energyrelated $\mathrm{CO}_{2}$ emission increases are assigned to a few major macro-economic variables, the result is that increased income is the cause of $1.9 \%$ of emission growth, but this is offset by an equivalent reduction of carbon and energy intensities. The rate of population increase (1.4\%) is in fact roughly equivalent to net emission increase (SR, p. 178).

Three quarters of energy-related GHG emission increases by 2030 will be produced by developing or emerging countries. Even if industrialised countries (countries in Annex 1 to Kyoto protocol) were able to reduce their emissions to zero by 2050 , the rest of the world would still have to reduce emissions by $40 \%$ compared to the reference (BAU) scenario to achieve $550 \mathrm{ppm}$ of $\mathrm{CO}_{2} \mathrm{e}$ concentration (SR, p. 206). Figure 7 indicates the magnitude of reductions to achieve by comparison with the BAU scenario.

Stabilisation of the current GHG concentration $(430 \mathrm{ppm}$ of $\mathrm{CO}_{2} \mathrm{e}$ ) would lead, at equilibrium, to a temperature increase of 1 to $3^{\circ} \mathrm{C}$, if aerosols did not minimize the impact. There is still a one-in-five chance that temperatures rise by over $3^{\circ} \mathrm{C}$ at that level.

Maintaining $2000 \mathrm{GHG}$ emission levels would lead to a $550 \mathrm{ppm}$ concentration around 2050 and $650 \mathrm{ppm}$ by 2100 (SR, p. 170). At the end of this century, the earth could reach temperatures unprecedented for three million years. The out-

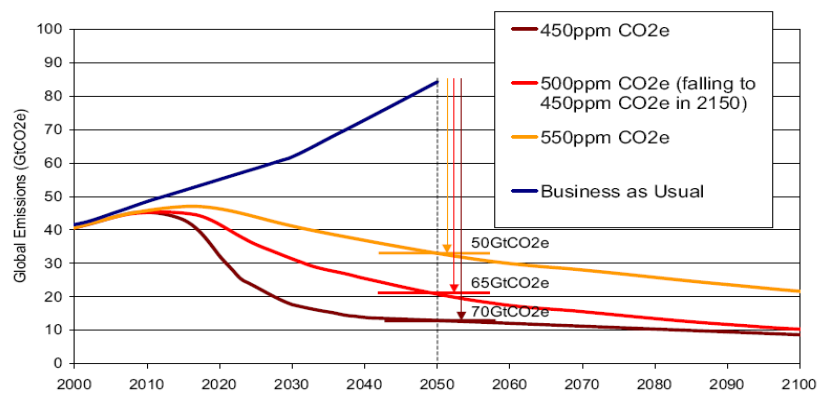

Figure 7. Comparison of stabilisation and BAU scenarios (from SR, p. 206).

come of an absence of GHG policy would be a significant increase in emission levels: BAU implies reaching $550 \mathrm{ppm}$ around 2035 (SR, p. 169).

\subsection{The impacts of climate change}

Sea levels rise much more slowly than temperatures, but will continue to do so over a long period (between 10 and $88 \mathrm{~cm}$ by 2100). However, by around 2050 sea-water flooding and coastal protection could become a problem in South-East Asia, small islands and many conurbations: Tokyo, Shanghai, Hong Kong, Calcutta, Karachi, Buenos Aires, London, New York, etc. (SR, p. 76).

From one study (Thomas et al., 2004), a temperature increase of 1 to $2^{\circ} \mathrm{C}$, if it occurred in a short time, could be sufficient to cause the extinction of 15 to $40 \%$ of natural species because of the loss of areas having suitable conditions of living for the concerned species (SR, p. 80). Nature reserves could progressively experience climates much less favourable to the species they are supposed to be preserving.

Melting glaciers could increase the risk of flooding during the wet season and increase dry season water shortages for one sixth of the global population (Indian sub-continent, parts of China, the Andes in South America). Water reserves for the dry season provided by the Himalayan glaciers might suffer a two-thirds reduction by 2050 (SR, p. 104). And yet, in 2000 over 200 million people were living in floodplains.

The likelihood of suddenly changing regional weather patterns in certain areas will increase with time, in particular as regards the monsoon in Asia and El Nino in Latin America. Climate change will also involve greater seasonal and annual variations, without the various types of excesses (droughts and floods) offsetting each other. An increase in frequency by a factor of 10 of these extreme situations is to be expected for a $3^{\circ} \mathrm{C}$ rise in temperature. From Munich Re estimates, the heat wave in Europe in 2003 killed at least 35000 people and generated agricultural losses worth $\$ 15$ bn (SR, p. 132). By about 2050, extreme climate events could inflict annual damages of between 0.5 and $1 \%$ of GWP (SR, p. 132). In 2005, another exceptional year, damages already totalled 
some $0.3 \%$ of GWP. The cost of flooding in the United Kingdom could increase threefold and reach approximately $0.3 \%$ of GDP in 2050 (SR, p. 133). An indirect effect could be the growing difficulty in insuring certain assets because of their location (coastal areas, regions vulnerable to flooding, etc.), which would reduce possibilities of adaptation.

In areas affected by reduced rainfall such as California, hydroelectric production could be cut by $30 \%$ in the event of a $4^{\circ} \mathrm{C}$ temperature rise (SR, p. 126).

Climate change will radically modify food production because of interacting factors: the extinction of species essential for the ecology of agrosystems (pollination, etc.); the increased frequency of floods and droughts; more extensive fires in forests and crops; the development of crop-destroying pests; increased tropospheric ozone with a negative influence on crop yields.

The fall in agricultural income and the effects on health of a deteriorating environment will inhibit agricultural productivity (preference for less risky crops in spite of lower productivity), investment and the dissemination of effective techniques. In a number of cases, disinvestment (selling of assets to cope with survival problems) will ensue and the poverty trap will persist, not to mention pressure on public resources (lower tax revenues, extra fiscal expenditures). The solvency of people concerned will be affected as will their capacity to meet their essential needs through trade. It will be more difficult to meet development goals analogous to those of the Millennium.

In proportion, damages generated by climate change will affect the developing countries welfare much more than industrialised countries because of four factors: their geographic location; their strong dependence on agriculture; their higher vulnerability to lack of resources; their low rate of insurance (under $1 \%$ of losses due to natural disasters from 1985 to 1999 were insured in low-income countries) (SR, p. 99). For a $2-3^{\circ} \mathrm{C}$ increase in temperature, the extra number of people exposed to famine could be as high as 30 to 200 million. As a result, since developing countries will be those experiencing the greatest difficulties in adapting, large transfers from industrialised countries will be required to achieve the same development goals as in a no-climate change scenario.

Climate change tends to amplify disparities between rich and poor regions as regards health. Since 1970, according to the World Health Organisation (WHO), due to increased mean temperature and more frequent and severe heat waves, climate change is already responsible for over 150,000 deaths each year through increasing incidence of diarrhea, malaria and malnutrition, predominantly in Africa and other developing regions. ${ }^{6}$ Just a $1^{\circ} \mathrm{C}$ increase in global temperature above pre-industrial could double annual deaths from climate change to at least 300000 and this to happen by 2030 (SR, p. 75).

\footnotetext{
${ }^{6}$ Such estimates are taken from Patz and al. (2005).
}

By 2050 , there could be as many as 200 million additional permanently displaced persons due to climate upheavals (SR, p. 56); in 2000, climate refugees were as numerous as those fleeing political and religious persecution or ethnic conflicts.

The combination of these physical and economic changes will probably lead to tourist flows being modified, with as a result, significant loss of income for some regions and gains in others. This will in turn lead to new investment flows in tourist industry infrastructures.

\subsection{Policies to combat climate change}

The cost of energy represents on average less than $5 \%$ of the variable costs of production activities, and 3\% in the UK (SR, p. 255).

In the case of the United Kingdom, if emission reduction were to cost on average 30 euros $/ \mathrm{tCO}_{2}$, this would represent an overall increase of $1 \%$ in consumer prices (SR, p. 256). The economic impact would be equivalent to an 11 dollars increase per barrel of crude oil.

A complete halt to deforestation, which currently represents $20 \%$ of total GHG emissions, could be achieved for an average cost of no more than $\$ 5 / \mathrm{tCO}_{2}$ and even possibly $\$ 2$ (SR, p. 217). Difficulties would be institutional and political (rule of law, incentives).

In 2005 waste produced $1.4 \mathrm{GtCO}_{2} \mathrm{e}$ of emissions annually, half of which was due to landfill and the rest to waste water treatment. Programmes for diminishing the flow of waste through recycling and reuse should reduce emissions significantly. By 2020 , according to the IPCC, $0.7 \mathrm{GtCO}_{2} \mathrm{e}$ could be avoided, of which three quarters at negative cost and the remaining at an average cost of less than $\$ 5$ per tonne of $\mathrm{CO}_{2} \mathrm{e}$ (SR, p. 218).

Carbon capture and storage (CCS) should play a decisive role in reducing emissions. The IPCC special report on CCS suggested it would provide between $15 \%$ and $55 \%$ of the cumulative mitigation effort up to 2100 (SR, p. 525). If all new thermal power stations (coal-, gas- and fuel oil- fired) were equipped with CCS, global emissions could be reduced every year by $17 \mathrm{GtCO}_{2}$. In this way, $46 \mathrm{ppm}$ would be saved each year by 2050 (SR, p. 223).

Emission gains obtained through substituting biofuels for fossil fuels vary considerably (10 to $90 \%$ ) depending on the resources and systems used. Systems with the most potential would be those using lignocellulose materials. Two to three $\mathrm{Gt} \mathrm{CO}_{2}$ e per year in 2050 could be saved at a cost of under $\$ 25 / \mathrm{tCO}_{2} \mathrm{e}$.

Including the six Kyoto Protocol GHGs instead of focusing on $\mathrm{CO}_{2}$ alone can reduce the cost of a given objective of medium term reduction (2030) by 30 to $40 \%$ (SR, p. 245). In the longer term, the effect is lessened because of the much shorter life of some GHGs $\left(\mathrm{CH}_{4}\right)$.

Globally, energy subsidies in 2005 amounted to $\$ 250 \mathrm{bn}$, of which 90 for oil and over 50 for coal (SR, p. 269, 278) This is approximately the same amount as the extra annual 
investment budget needed to implement a strong policy for the prevention of climate risk by 2030 .

If instead of accepting an average cost of $1 \%$ of their GDP, the $20 \%$ richest countries benefiting from $80 \%$ of global revenues, were willing to pay an additional $20 \%$ to reach $1.2 \%$ of their GDP, the remaining $80 \%$ of the world population could pay only $0.2 \%$ of their GDP. By 2050 , that would represent an annual transfer of $\$ 200$ bn (SR, p. 259).

\section{Two additional comments on climate policies}

The type of action best suited to deal with climate problems, as regards the theory of risk (effect of uncertainty concerning damage functions and abatement costs on the best choice of instruments, by price - carbon tax- or by quantity - emissions caps-) is a combination of two components: in the long term, what is needed is quantitative objectives defined as atmospheric GHG concentrations whereas in the short and medium term, priority has to be given to flexibility and economic efficiency. Quota trading or taxation is therefore required to adjust pathways to the long term objective in a flexible manner.

In spite of appearances, the problem of adapting to climate change has some features of public goods (action benefits not solely enjoyed by the investor). This is true in particular for scientific research and the dissemination of information on possible techniques, but also for land use planning and insurance schemes. Both national and international policies are therefore required to support adaptation, even though an important portion of adaptation is the result of personal, corporate or local authority commitment.

\section{An assessment of the critical debate triggered by the Stern Review}

\subsection{A mixed reception}

Even before publication, the Stern Review was the subject of divergent appraisals which became even more heated after it was released. It received the solemn validation of the British Prime Minister and was also the subject of extensive media and political attention. It modified the spirit of the Conference of the Parties to the UN Framework Convention on Climate Change, held in Nairobi in November 2006, although it failed to lead to the adoption of a timetable for the setting up of a post-Kyoto international organisation. It was welcomed by four Nobel prize laureates in Economics (James Mirrlees, Amartya Sen, Robert Solow, Joseph Stiglitz), by other economists (John Quiggin, Claude Henry, inter alia), by economic experts on climate change, such as Michael Grubb (Cambridge University and Carbon Trust in the United Kingdom) and by other international personalities. Other economists formulated critical comment.

Some expressed their reservations in moderate tones (D. Maddison, H. D. Jacoby, et al.) whereas others adopted a more severe view on crucial points such as discounting (P. Dasgupta, W. Nordhaus, M. Weitzman, G. Yohe) and some responses were even violently hostile (R. Tol) (see Box 5). Criticisms by climatologists (R. Lindzen, F. Singer and other climate change skeptics, see Box 6) and personalities standing at the border of science, ideology and politics, such as Bjorn Lomborg (2006), should also be mentioned, as should the editorial writers in magazines ${ }^{7}$.

The Stern Review did not arrive on completely virgin ground as regards economic studies on climate change. Some economists, such as William Nordhaus, have been working on the subject since the mid $1970 \mathrm{~s}^{8}$ and many energy economists have invested that field since the early nineties. In so far as the Stern Review's message contradicts quite radically the hierarchy of costs and recommendations proposed by many economists, it is only to be expected that it attracts careful scrutiny and criticism.

Richard Tol is professor in Hambourg, Vrije and Carnegie Mellon universities
and militates in favor of strategies for adaptation to climate change. He wrote in
November 2006: "The Stern Review is very selective in the studies it quotes on
the impacts of climate change. The selection bias is not random, but emphasizes
the most pessimistic studies. The discount rate used is lower than the official
recommendations by HM Treasury. Results are occasionally misinterpreted. The
report claims that a cost-benefit analysis was done, but none was carried out.
The Stern Review can therefore be dismissed as alarmist and incompetent. (...)
unsound analyses like the Stern Review only provide fodder for those skeptical
of climate change and climate policy." In an interview on the BBC (Radio 4)
on January 26, 2007, he was even more devastating: "There is a whole range of
very basic economics mistakes that somebody who claims to be a Professor of
Economics simply should not make. (...) If a student of mine were to hand in
this report as a Master thesis, perhaps if I were in a good mood I would give him
a "D" for diligence; but more likely I would give him an "F" for fail."

Box 5: An example of the tone of harsh criticism by a climate economist, R. Tol.

Most climatologists dismissing the scientific basis of the Stern Review are also
on the list of signatories of an appeal addressed to the Canadian Prime Minister
Stephen Harper in April 2006, asking him not to commit to a climate policy, said
to be irrational and dramatically costly. Claiming that involving human respon-
sibility in the climate issue has no scientific base, the 60 scientists who signed
this letter were asking Harper to organize a broad contradictory public debate on
the scientific foundations of the Kyoto Protocol. See Clark et al. (2006). They
were almost immediately contradicted by other letters from 80 scientists and by
the Canadian Society of Meteorology and Oceanography and its 800 members
reaffirming their trust in IPCC expertise (Woodbury, 2006).

Box 6: Climatologists who severely criticize the Stern Review are those skeptic scientists denying human-made climate change.

The criticisms vary, but on the whole, address the modelling part of the Review, although the Stern Review Team stated that they considered the exercise as additional to the empirical description of damages incurred and not to be taken at face value. The most acerbic criticisms are based either on an overly hasty perusal of the Review, or on excessive attention given to a few discrepancies and methodological approximations or else - and this is paradoxical in the light of the tone of some critics - on an incorrect appreciation

\footnotetext{
${ }^{7}$ See the list of critiques of the Stern Review in the "references" section.

${ }^{8}$ See for instance Nordhaus (1977).
} 
of the meaning of the economic concepts (when critics disregard the specific context in which concepts and tools are relevant and oversestimate the general scientific value of specific assumptions), or on fundamental points of disagreement more related to ethics than to economics.

\subsection{Three main lines of economic criticism}

Critical comment was mostly focused on three main themes: 1) the Stern Review Team used the scientific literature selectively and the bias systematically favoured the worst case scenario; 2) they made technical errors (counting risks twice over, refusing to take into consideration the considerable attenuation of net damages obtainable via adaptation strategies, forgetting some of the economic costs of prevention policies, discrepancies between the damages as described and economic growth assumptions, in Africa in particular, etc.); 3) they manipulated the economic concepts and tools, in particular the discount rate, so as to paint the most alarming picture of expected damages if the international community failed to take early energetic action.

In the following, I am going to report the debates but also give my own arguments and viewpoint. My general assessment is that if the conclusions of the Stern Review are, on the whole, right, but sometimes for the wrong reasons as said by Weitzman (2007) and Yohe, Tol and Murphy (2007), the harshest criticisms are wrong or disputable because they are based on bad or disputable arguments.

The first line of criticism displays a misunderstanding of the Stern Review approach, which is based on risk and uncertainty economics. In this approach, close attention must be paid to assumptions which may be seen as rather extreme but can muster a sufficient degree of scientific consideration even if they are not yet "certified" or validated". Unlike a number of previous reports, the Stern Review is not restricted to average values and "best guesses" and explicitly refers to the rationale of the precautionary principle, although the latter is not formally entered in the modelling. As a matter of fact most previous economic work has been considering scenarios implying an expected temperature increase of $3^{\circ} \mathrm{C}$ and few have systematically explored the implications of the global climate erring in much higher values. This is a matter of attitudes ${ }^{10}$, but also of work in progress of climatologists

\footnotetext{
${ }^{9}$ It has been shown by Henry and Henry (2002) that it would be irrational for decision-makers to consider only the data for which a determined probability distribution exists. Ambiguous scientific data, in Ellsberg's terms (1961), implying only probability ranges or imprecise probabilities for some events or states of the world, also have to be considered for devising a more enlightened and rational policy.

${ }^{10}$ It is only recently that the issue of how to treat extreme values by statistical models and cost-benefit analyses has been raised, thanks to Tol (2003) and Weitzman (2007a and b).
}

and economists since $2001^{11}$. The Stern Review is rightly considering a broader scope of possible climate evolutions and gives an explicit formal treatment to the possibility of more frequent and intense extreme events. All this has been integrated in the probabilistic approach of the PAGE 2002 IAM with the help of Monte-Carlo simulations, which most other models do not provide.

Investigating the second line of criticism would lead to technical discussions which are beyond the scope of this survey. Some of the points are of secondary importance. Others express disagreement with the framework chosen for the Stern Review. This is the case for adaptation, which deserves a detailed discussion (see below).

For several economists, the gist of the situation as described by the Stern Review is to be attributed to an excessively low discount rate which they see as unjustifiable because it is out of phase with empirical observations on current attitudes to saving and risks on capital markets. As a result, the recommendations (immediate action on emission trajectories so as to trigger a global downturn of emissions before 2020 in order to avoid exceeding a long term concentration of $550 \mathrm{pm}$ of $\mathrm{CO}_{2} \mathrm{e}$ ) are considered unrealistic and devoid of any rational basis in the light of the disproportionate economic costs involved ${ }^{12}$. Let us begin by considering this case on discounting.

\subsection{The key role of the social discount rate}

Martin Weitzman (2007a) begins his review of the Stern Review by stating that, by instinct, most economists would choose a triple 2 for determining the proper value of the discount rate: $\delta=2, \eta=2, g=2$, which gives $r=6 \%$. The Stern Review adopted respective values of $\delta=0.1, \eta=1, g \sim 1.3$, which gives around $1.4 \%$ for $r$. Was this low discount rate unreasonable and ungrounded? Certain analysts (Nordhaus, Weitzman, Tol, Yohe...) reason as though the object was to set a rate applicable to investment projects to be made in the near future, so that they then refer to current terms on the capital market or to attitudes to savings in order to argue against the Stern Review approach. On this basis Nordhaus suggests $\delta=3$ as a proper value for the pure time preference. But the Review is totally explicit about the reasons why its authors think this line of reasoning is not appropriate to examine a global problem such as climate change for a time span extending to 2200 and in fact well beyond. Their choice for the value of this variable $\delta$ is grounded in an ethical postulate: the utility of each human being should be treated the same

\footnotetext{
${ }^{11}$ If we can find few early attempts to take account of possible catastrophic events in Integrated Assessment Models, they have been modelled as economic events, not firstly as physical events, as is pointed out by Wright and Erickson (2003).

${ }^{12}$ Wanting to avoid huge short term costs, Yohe, Tol and Murphy (2007) propose that policies to be framed on the basis of a carbon value not exceeding $\$ 15$ per $\mathrm{CO}_{2}$ ton in the short term and increasing at the interest rate to reach $\$ 30$ by 2020 .
} 
way independently from time and geographical contingencies. As Thomas Schelling (1995) put it, the usual justification of the pure time preference - the psychological notion of impatience - does not make sense when the issue at stake is the future of the planet's climate in centuries: we feel no impatience when considering possible transfers of wealth between year 2100 and year 2166... However Schelling supported a mixed ethical position acknowledging legitimacy to an unequal willingness of people to redistributing income to unequally distant people by time and geography, what he called "depreciation", quite a different ethical basis from the Stern Review for making decisions.

In parallel the well-known Cambridge economist Partha Dasgupta (2006), in his own review, accepts the ethical position of the Stern Review for $\delta$, but criticizes the value of $\eta$, that he thinks should have been increased by a factor between 2 and 4 . This proposal would imply a greatly increased social willingness to redistribute wealth from rich to poor, and subsequently limit the transfer from the present towards the future, supposed to be wealthier. With a factor 2 for instance it would be justified to take 100 from the rich if it allows to increase the income of people 10 times less wealthy by only 1. It is hard to see how such transfers can be grounded on the observation of real practice in contemporary societies, which is the rationale of Nordhaus and his likes. Meanwhile both Nordhaus and Dasgupta converge to support a discount rate of about $4.5 \%$. But the Dasgupta's position is different in trying to reconcile economic realism, like Nordhaus, with formal coherence in the theory of discounting and a normative view favouring the poorest of the present generations.

The problem of coherence raised by Dasgupta is the following: in a very simplified model assuming that growth is the exclusive outcome of capital investment and the social rate of return on investment is $4 \%$, with the values $\delta$ and $\eta$ of the Stern Review, the rate of savings should be tremendous, reaching $97.5 \%$ of present income, which is by no means realistic and acceptable. Although impressive, the argument is not quite convincing since this reductio ad absurdum begs the question: there is a discrepancy between the assumption of the Stern Review of a long term per capita rate of growth of $1.3 \%$ and a social rate of return on investment of $4 \%$ and, as pointed out by Delong (2006), the model used is also disputable since it ignores technical progress, the most important source of growth in the real economy. By injecting technical progress in the same simplified model, Delong shows that it is possible to reconcile the values of the Stern Review with a reasonable rate of savings (around 22\%) asked for to present generations.

By crossing criticisms and proposals of Dasgupta and Nordhaus, the choices of the Stern Review paradoxically emerged as rather sound, while, at the same time, they raise considerable issues about the legitimate conditions for making collective ethical choices. Whatever ethical judgment is made on the weighting of the welfare of generations in the distant future, along the lines of Schelling or those of the
Stern Review or yet other ones ${ }^{13}$, it cannot be deduced from the manner in which our contemporaries organise their private affairs - saving more or less of their income or buying more or less insurance policies. There are several reasons for that. The most evident one is that individual life horizon and the horizon of mankind do not coincide: choices framed by the first one cannot have precedence when issues pertinent to the second are raised. The second reason is a case of market incompleteness: generations alive today cannot avail themselves of economic mechanisms to reveal their well-considered ethical preferences after giving due consideration to their vision of mankind in the future and how best to deal with a world a large part of which does not take part in the market goods universe. The standard situations of economic choice put forward by tenants of realism do not fit the framing of choices imposed by the climate change issue. They make a mistake against reality.

The basis of positions of Nordhaus or Tol (2006) calling for a realistic approach of social preferences could only be justified by making two ethical assumptions: first, ethical choices are exclusively a private affair, even for determining the fate of global public goods, and the coherence of individual preferences in privacy makes it possible to extrapolate from ordinary consumer choices to reveal what individual ethical preferences are regarding long run climate issues; second, public choices have to mimic private consumer preferences. Both assumptions, to my view, express a badly understood moral individualism. When the destiny of the human community is at stake, ethical choices have to be placed in the sphere of public deliberation and framed by the moral values crystallized in fundamental law references and institutions. Let us take from Mark Sagoff (1988) the idea that it is a mistake in the use of concepts to confuse the determination of consumer preferences in privacy and that of preferences of citizens in the public arena, though in both cases individuals are invited to form and express a judgment. We know from the work of Michael Walzer (1983) and Luc Boltanski and Laurent Thevenot (2006) that, in Western democracies, several principles of justification coexist, which put in order different parts of our social lives and from which are derived ordinary norms of justice. It is critical not to confuse all of them, as is unhappily frequently done by economists seeing the attention they give to consumer preferences on the market as the highest expression of their attachment to democracy and rationality.

The position adopted by the Stern Review, that is granting the same weight to the utility of any individual irrespective of date of birth, is as orthodox as it is possible to be from the viewpoint of utilitarian philosophy which is the matrix of welfare economics that Stern, Nordhaus, Dasgupta, Tol

\footnotetext{
${ }^{13}$ Nordhaus (2007) rightly underlines there is no unique commonly accepted ethical framing for making decisions touching intergenerational justice. See for instance Dobson (1999), Page (2006), Tremmel (2006).
} 
and other have adopted for normative purposes. The fact that this does not reflect current choices in a society engrossed in present-day issues is irrelevant since it only confirms the radical distinction between positive and normative worlds. What would be the point of taking observed current behaviours as a foundation of normative choices for the global future since those behaviours are, on the aggregate level, radically unsustainable and we ${ }^{14}$ want a sustainable future?

Clearly, discounting is the chink in the armour of any economic approach involving decisions with effects extending into the very distant future. A technical criticism that can indeed be made of the Stern Review is that it chose to allow a single variable to synthesize four different types of considerations in one aggregate value: subjective treatment of risk for oneself (threat to one's own life or one's income), attitude to wealth inequalities (from rich to poor or the reverse), inter-generational ethical standards of equity and, last but not least, long term preferences between producible and non-producible goods (natural resources and life supporting ecological systems). The Stern Review Team in their reflections of 12 February 2007 in fact acknowledged the difficulties of having to take account too many dimensions to determine the value of a single variable. Although all modelling exercises need the use of tractable formalisms and involve compact formulations of concepts, future work should try and disentangle these various aspects.

Let us focus on the fourth variable. Strictly speaking, to give acceptable results, a given discount rate has to be applied to a basket of goods and services assessed with a correct structure of relative prices. When the economy is made of two types of goods, those producible by human activity and those non-producible extracted from the environment, we know that the relative prices of non-producible goods should progressively increase over time because of their growing scarcity - less supply for more demand. In a perfect market economy, the rate of increase of prices of non-producible goods should equate the interest rate paid on the capital market. Although this focus on changing patterns of relative prices, which generalized the Hotelling's rule for depletable natural resources, was established in a general equilibrium framework for a decentralized-disaggregated economy with $n$ goods by Edmond Malinvaud in $1953^{15}$, then emphasised

\footnotetext{
${ }^{14}$ One criticism against the Stern Review is that its assessment was arbitrarily based on personal ethical positions of the authors, not on due attention to preferences of the people. This criticism is not technically acceptable and is based on confusion, as shown earlier. But wanting a sustainable future for mankind is no more a matter of personal taste, since it has been acknowledged by many international conventions and national legal systems. For instance, in France, a constitutional text - the Environmental Charter - obliges public policies to target a sustainable development.

${ }^{15}$ More precisely, Malinvaud (1953) established that decentralized agents need to have a complete intertemporal set of prices for all goods and not only the intertemporal price of the numeraire (the discount rate) and the present relative prices of other goods in order
}

thirty years ago by Marcel Boiteux (1976), and sometimes acknowledged in public economic guidelines ${ }^{16}$, most applied economic analyses do not take an explicit account of this structural shift of prices. It is the case of aggregate optimisation models of climate change policies that stick to a more tractable framework of aggregate output and consumption and an overall per capita rate of consumption growth, instead of introducing at least a two-sector representation of the economy. In practice, this comes back to considering the output structure and relative prices as unchanged through time.

Quite surprisingly this issue has not been raised by the most eminent Stern Review critics who have reasoned only on the basis of an aggregated consumption or gross product flow without pointing out the shift of long term relative prices to reflect an asymmetrical evolution of affluence: increased scarcity in one side and increased affluence in terms of private goods in the other side. Although the Stern Review is dedicated to an assessment of possible evolutions of critical environmental conditions, the discussion by critics were put in terms considering as self-evident that future generations will be much wealthier on the whole than present ones. It is true that the Stern Review itself adopted such a framing, which coherently leads to the conclusion that serious mitigation policies are the best means to preserve long term growth. However as Roger Guesnerie $(2004,2007)$ puts it in his comments of his own two-sector model addressing this issue: "What we give to future generations is not an extra endowment of private good, that they will get in much higher quantities than us, but an extra endowment of "resources" that could be vital for them, even if we are not sure of that. We are then doing the only useful thing we can do for our heirs. Pushing the model to its limit, we should give, if we want to behave in an ethically responsible way, the same utility value to a degradation of the environment affecting a far time-distant generation as we do if this degradation is affecting ourselves." (Guesnerie, 2007:460).

In the same spirit Thomas Sterner and Martin Persson (2007) have showed that letting prices to be adjusted to the increasing scarcity of natural, non producible assets would lead to results at least equivalent and presumably significantly more stringent than those of the Stern Review ${ }^{17}$. They have used for their demonstration the DICE model worked

to achieve an efficient allocation of resources.

${ }^{16}$ For instance the Office of Management and Budget in the US released in January 1996 guidelines for the analysis of federal regulatory reforms. The necessity to consider changes in relative prices is briefly noted, quoting the case of certain environmental resources (p. 10-11), but the focus is placed on the concern that this should not be reflected through an adjustment of the discount rate.

${ }^{17}$ This would be the case if we combined both assumptions: changing relative prices and a low social discount rate similar to the one chosen by the Stern Review. Then the policy target should be a GHG concentration maintained below $450 \mathrm{ppm}$ and perhaps 400. 
out by Nordhaus, and with these new, but sound assumptions, obtained results opposite to those of the author of DICE.

Beyond the points already discussed, two additional insights deserve to be mentioned. First, the formalisation and assumptions adopted by the Stern Review regarding the discount rate can be seen as an indirect, unorthodox, approach of the increasing weight given to natural assets and services due to their increasing scarcity in the long term. Another interpretation is given by Weitzman (2007a). Not satisfied with the key values chosen by the Stern Review for the discount rate, he suggests they may be seen as an indirect way, and not the most appropriate one, to take account of possibilities of really catastrophic climate evolutions putting survival of huge numbers of humans and perhaps mankind into serious difficulty; in technical terms, the inherently-thickened left tail of distribution of events representing highly uncertain but extreme catastrophic evolutions should dominate the standard assessment of welfare impact. For him the prospect of climate change is mainly an issue of buying insurance against such catastrophic possibilities, not of fine-tuning the distribution of consumption between generations. Hence his final suggestion that the Stern Review may be right for the wrong reasons.

\subsection{An ambiguous adaptation}

If scientists say right and current observations of concrete manifestations of climate change are not a dream, some global climate change is inescapable and is already on track. Any responsible climate policy has to consider the issue of an adaptation policy. Several questions have to be addressed: which balance should be found between the means allocated to adaptation and mitigation respectively? What is the content and timing of a clever adaptation strategy? Who should be the main actors in charge of taking action and who should pay for those measures? And so on.

\section{An excessive asymmetry between present and future generations}

Ambiguity begins when the adaptation theme is also used by some scholars as a means to dismiss the necessity of a strong mitigation approach and make strong attacks against the Stern Review for having systematically underestimated the possibilities of victims of damages from climate change to adapt quite easily. Following on Lomborg's footsteps (Lomborg, 2001), Tol (2006) sees in the capacity to adapt a factor of damage abatement of such magnitude that there is only little left to justify prevention policies. If we push the argument to its ultimate limit, there is an adaptive solution to every problem. The future world imagined by Tol and his likes is a flexible one where people can immediately adapt to events and catch opportunities by using available resources, where technical progress has prepared ready solutions to any problem, where there are no bad synergies between various types of impacts and events and no cumulative impacts of repetitive threats and disasters. On the contrary, according to its description, the economy of present generations would demonstrate few possibilities to adapt to climate challenge or climate policies, without huge economic and social disorder. The argument is then tailored in terms of efficiency: it would be much more efficient to bet on the multiform adaptation capacity of future generations than on the difficult, costly and poorly effective mitigation actions that present generations could take. This view is disputable for several reasons.

\section{Adaptation capacities depend on previous investment}

The implicit assumption underpinning the argument is that adaptation capability is a natural and direct function of wealth. It may look attractive at first sight, but not so convincing at second sight. Think of contemporary experience of the wealthiest countries in the world, deemed incapable for nearly twenty years to adapt to the new carbon economy. How many times have we heard that the US, for instance, could not afford a significant climate policy because it would imperil the American way of life and crash against structural factors such as car transportation dependency, the territorial spreading of cities, threats of unemployment in regions depending on coal and oil extraction, and so on? In fact if those arguments were not just bad rhetoric, they tell us that adaptation is not so much a function of gross wealth than of three main variables: the economic surplus - the overall investment capability- produced by an economy to transform and renew its infrastructure, a concept that has a financial dimension and a real one (human capital, $R \& D$ ); the level of irreversible commitments to high-carbon profiles fixed by passed choices into territorial features, infrastructures and technologies; and the level of diversity of opportunities supplied by the current running of the economy and easily accessible to everyone to meet a given need. Having the capability to finance investment is mostly valuable if there are at the same time new technologies and rich human competences ready to be mobilized. The three variables - surplus, irreversibility and diversity - depend critically on investment by previous generations in developing such potential of future adaptation. It is not a free gift that any growth trajectory can offer.

Realizing that the potential to adapt depends on previous investment reinforces the methodological choice of the Stern Review of not integrating adaptation policies attributed to future generations in the calculation of a concept of net damages, as Tol harshly asked. What the Stern Review did to this regard was to integrate spontaneous adaptation actions from decentralized agents when they are mentioned in the literature surveyed, not those that would need public policies and previous investments to be implemented. The reason is straightforward: in a cost-benefit framework, it is necessary to assess possible gross damages imposed by climate change in order to calibrate how much should be invested in 
developing adaptation capacities. There is no point in using the Lomborg's fallacious argument according to which future problems do not exist since future generations will "likely" solve them (Lomborg, 2001), without seeing that in order for future generations to solve those problems it is necessary for previous generations to take the issue seriously and actively prepare the solutions, while avoiding to fix rigid carbondepending productive capital, infrastructures and land use. Coherently the Stern Review considers adaptation policies in chapters 18 to 20 as an answer to their assessment of possible damage.

So the extent of damages as depicted by the Stern Review is realistic in that it does not assume that we are living in the best of all worlds, and that the world of the future is likely to move much closer to perfection. It is however true that normative choices (equal attention to the welfare of all generations) and recommendations made (organizing substantial financial transfers to developing countries, for example) postulate a form of altruistic determination or universally shared ethics among present generations which are hardly attuned to this realistic attitude.

\section{Why worry for the welfare of people that will be much richer than us?}

The co-existence of steadfast long term economic growth at an annual rate of $1.3 \%$ together with a possible catastrophic picture of damages inflicted by climate change is puzzling. On this point, Tol (2006) and a few others (for instance Tol and Yohe, 2006; Weitzman, 2007) argue as follows: according to the Stern projection, the inhabitants of our planet in 2200 will be 10 to 12 times as rich as those of 2007 . To what extent should the people living in 2008 worry about the fact that the climate could take 20 or $30 \%$ off this future wealth? Those living in 2200 will still be eight times richer!

Beyond the fact already mentioned that the concept of wealth has to split between the part obtained by the consumption of private goods and the part depending on ecological services, since their evolution will be extremely contrasted in a baseline scenario of climatic laissez-faire, beyond the Weitzman's preoccupation for the possibility of extreme climatic evolution leading mankind to a terra incognita and perhaps a threat for survival, I just want to make a complementary point. It will counter-balance this apparent evidence that we should not be too much concerned by the future generations destiny. Assuming a constant rate of growth of $1.3 \%$ during two centuries is a useful convention to achieve calculations, but does not bring any guarantee that it will be the case. Taking account of the surprises brought by history, it is quite possible that growth will collapse at some moment, because of environmental crises or for other easily conceived reasons (a new world war, a huge economic crisis, an extremely devastating pandemic). Because of the huge inertia of the physics of climate change, those emissions released between the XIXth century and 2050, if nothing is done to curb their growth, will possibly provoke dramatic changes in the climate for a very long time - several centuries, whatever the level of welfare accessible to future generations. The idea that wealth will surely compensate for climate hazards is a purely subjective belief that becomes a fallacy when it is dressed as a scientific fact. There is no serious means to establish a probability for such a possibility: climatic catastrophes without wealth.

\section{The ethical point}

Let us forget, for a while, all the arguments introduced up to now that could make us somewhat suspicious about the way adaptation is used by some critics of the Stern Review, and consider the following question. Even if it would be less costly for future generations to adapt to climate change than for present generations to try and control their emissions in a way allowing GHGs atmospheric concentrations not overshooting $550 \mathrm{ppm}$ of $\mathrm{CO}_{2} \mathrm{e}$, would it be legitimate for present generations to transfer the burden in the name of economic efficiency since this transfer cannot be negotiated in the context of a free exchange or with the agreement of future parts? The basic fact to consider is that climate change is a stock externality damaging a multitude of future generations, but its counterpart is just benefits for the sole generations having lived between 1850 and 2050. This distributional asymmetry raises an ethical issue that is not appropriately caught by the dressing in terms of efficiency along the line of the Kaldor-Hicks criterion of potential compensation. The latter can make sense in a political community in which all affected stakeholders have economic mechanisms and institutional procedures to express their viewpoints and transform potential compensation into a real one, but not in an asymmetrical intergenerational context of relations with distant generations. At least, on ethical grounds, it would be important for the supporters of future adaptation to support a strong present mixed investment strategy aiming both at mitigating emissions and developing potential for future adaptation.

The only way to escape the moral obligation not to leave the climate costs to future generations for our own benefits is to demonstrate that our care for future generations will be better served by alternative actions than by mitigating climate change. The argument is often put forward. But due to the quick obsolescence of past investments in numerous technologies and industrial productive capacities, letting behind abandoned useless industrial sites and a lot of waste, we should think twice and really scrutinize which sort of alternative strategies will provide a better-guaranteed utility to future generations than maintaining a liveable global environment. 


\section{Conclusion}

Despite all the criticisms, almost all the economists critical of the Stern Review agree in emphasising that the climate problem is a genuine one deserving an immediate and international commitment in favour of some degree of prevention and adaptation. They also agree that to achieve this, a cost-effective policy involves the use of economic instruments which give prices to carbon, and a vigorous stimulation of research to give birth to new low carbon technologies. The practical scope of the methodological and theoretical points of disagreement is therefore confined to selecting the target (a GHG concentration between 450 and $550 \mathrm{ppm}$, says the Stern Review) and to the timetable for controlling GHG emissions and developing investment in adaptation potential. The points in dispute are therefore the degree of structural reorientation of contemporary economies, the level of cost to be accepted in the short and medium term for the sake of preserving a distant future and the status to be given to the goal of preserving global environmental conditions. To a large extent they are ethical and political issues more than economic ones. Since the counterpart of GHG emissions is the production of goods and services for the benefit of present generations, the key feature of the issue is one of transfer of costs from those who take the benefits to others that will just have threats and hardship to this regard (Gardiner, 2006). Efficiency goals cannot escape to be reframed into ethical and even ontological issues in regard with the status to give to global ecological conditions of human existence and the prospect of threats for the moral or physical survival of mankind (Jonas, 1984). Dressing the whole discussion as an efficiency issue based on current consumer preferences, as some critics of the Stern Review do, is something of a deception and quite a misleading way to qualify the choices before us. By its main results and conclusions, the Stern Review puts us on the right track but, sticking to the standard economic conceptual framework and focusing on economic growth, has lost an opportunity to make also a conceptual breakthrough in line with the sustainable development paradigm.

Edited by: G. Mainguy

Reviewed by: two anonymous referees

\section{References}

\section{General scientific literature}

Barker, T., Qureshi, M. S., and Köhler, J.: The costs of greenhousegas mitigation with induced technological change: A MetaAnalysis of estimates in the literature, 4CMR, Cambridge Centre for Climate Change Mitigation Research, Cambridge, University of Cambridge, 2006.

Bazerman, M. H.: Climate change as a predictable surprise, Climatic Change, 77, 179-193, 2006.

Boiteux, M.: A propos de la 'Critique de la théorie de l'actualisation telle qu'employée en France', in: Revue d'économie Politique, 1-17, September-October 1976.

Boltanski, L. and Thévenot, L.: On Justification: Economies of Worth, Princeton University Press, 2006.

Clark, I., Murty, T., Patterson, R. T., Michel, F., et al.: Open Kyoto to debate - An open letter to Prime Minister Stephen Harper, Financial Post, 6 April 2006.

Dupuy, J.-P. and Grinbaum, A.: Living with uncertainty: from the precautionary principle to the methodology of ongoing normative assessment, Comptes rendus Geoscience, 337, 457-474, 2005.

Ellsberg, D.: Risk, ambiguity and the Savage axioms, Q. J. Econ., 75, 643-669, 1961.

Dobson, A. (Ed.): Fairness and Futurity - Essays on Environmental Sustainability and Social Justice, Oxford University Press, 1999.

Gardiner, S. M.: Protecting Future Generations: Intergenerational Buck-passing, Theoretical Ineptitude and a Brief for a Global Core Precautionary Principle, Chapter 8, in: Handbook Of Intergenerational Justice, edited by: Tremmel, J. C., Cheltenham (UK), Edward Elgar, 148-169, 2006.

Guesnerie, R.: Calcul Économique et Développement Durable, Revue économique, 55, 363-382, 2004.

Henry, C. and Henry, M.: Formalization and applications of the Precautionary Principle" Cahier du Laboratoire d'Econométrie de l'Ecole Polytechnique, no. 2002-008, available from: http://ceco.polytechnique.fr/fichiers/ceco/publications/pdf/ 2005-06-09-965.pdf, February 2002.

Hope, C.: The marginal impact of $\mathrm{CO}_{2}$ from PAGE2002: an integrated assessment model incorporating the IPCC's five reasons for concern, The Integrated Assessment Journal, 6(1), 19-56, 2006.

IPCC-WG1: Climate Change 2007: The Physical Science Basis Summary for Policymakers, Fourth Assessment Report, Geneva, February 2007.

IPCC-WG3: Technical Summary, in: Climate Change 2007: Mitigation, Contribution of Working Group III to the Fourth Assessment Report of the Intergovernmental Panel on Climate Change, edited by: Metz, B., Davidson, O. R., Bosch, P. R., Dave, R., and Meyer, L. A., Cambridge, Cambridge University Press, 2007.

Jonas, H.: The Imperative of Responsibility. In Search of an Ethics for the Technological Age, Chicago, The University of Chicago Press, 1984.

Lomborg, B.: The Skeptical Environmentalist - Measuring the Real State of the World, Cambridge (Mass.), Cambridge University Press, 2001.

Malinvaud, E.: Capital Accumulation and Efficient Allocation of Resources, Econometrica, 21(2), 233-268, April 1953. 
Nordhaus, W.: Economic Growth and Climate: The Case of Carbon Dioxide, The American Economic Review, 67(1), 341-346, May 1977.

Nordhaus, W. D.: The economics of hurricanes in the United States, Prepared for Snowmass Workshop on Abrupt Climate Change, Snowmass: Annual Meetings of the American Economic Association, available from: http://nordhaus.econ.yale.edu/hurricanes. pdf, 2006a.

Office of Management and Budget: Economic Analyses of Federal regulations Under Executive Order 12866, Washington D.C., 11 January 1996.

Page, E. A.: Climate Change, Justice and Future Generations, Cheltenham, Edward Elgar, 2006.

Patz, J. A., Campbell-Lendrum, D., Holloway, T., and Foley, J. A.: Impact of regional climate change on human health, Nature, 438, 310-317, 2005.

Schelling, T. C.: Intergenerational discounting, Energy Policy, 23(4-5), 395-401, 1995.

Thomas, C. D., Cameron, A., Green, R. E., et al.: Extinction risk from climate change, Nature, 427, 145-148, 2004.

Tremmel, J. C. (Ed.): Handbook of Intergenerational Justice, Cheltenham (UK), Edward Elgar, 2006.

Weitzman, M. L.: On Modeling and Interpreting the Economics of Catastrophic Climate Change, Harvard University, mimeo, 31 October 2007b.

Walzer, M.: Spheres of Justice - A Defense of Pluralism and Equality, New-York, Basic Books, 1983.

Woodbury, S. K.: Open letter to Stephen Harper, Prime Minister of Canada, http://www.cmos.ca/LettertoPM20Apr06.pdf, 20 April 2006.

World Resources Institute: Climate Analysis Indicators Tool (CAIT), online database version 3.0, Washington D.C., World Resources Institute, 2006.

Wright, E. L. and Erickson, J. D.: Incorporating Catastrophes into Integrated Assessment: Science, Impacts and Adaptation, Climatic Change, 57, 265-286, 2003.

\section{Specific comments on the Stern Review}

Akerman, P.: Stern's report scare-mongering, Sunday Telegraph (Australia), 5 November 2006.

Baer, P.: The worth of an ice-sheet - A critique of the treatment of catastrophic impacts in the Stern Review, 18 January 2007.

Byatt, I., Castles, I., Goklany, I. M., Henderson, D., Lawson, N., McKitrick, R., Morris, J., Peacock, A., Robinson, C., and Skidelsky, R.: The Stern Review: A Dual critique - Part II: Economic Aspects, World Economics, 7(4), 199-232, 2006.

Carter, R. M., Freitas, C. R., Goklany, I. M., Holland, D., and Lindzen, R.: The Stern Review: A Dual critique - Part I: the science, World Economics, 7(4), 167-198, 2006.

The Center for Science and Public Policy: The Stern Report - Some Early Criticisms, Washington D.C., November 2006.

The Center for Science and Public Policy: A Collection of Reviews on the Stern Report - Vol II, Washington D.C., February 2007.

Cox, S. and Vadon, R.: Running the rule over Stern's numbers, The Investigation, BBC Radio 4, 26 January 2007.

Dasgupta, P.: Comments on the Stern Review's Economics of Climate Change, University of Cambridge (UK), 12 December 2006, published as: Commentary: The Stern Review's Eco- nomics of Climate Change, National Institute Economic Review, 199, 4-7, January 2007.

Delong, B.: Partha Dasgupta Makes a Mistake in His Critique of the Stern Review, available from: http://delong.vox.com/library/ posts/tags/stern+review/, 29 November 2006.

Economics focus: Shots across the Stern, The Economist, 84, 16 December 2006.

Giles, J.: How much will it cost to save the world?, Nature, 444(7115), 6-7, 2 November 2006.

Gollier, C.: Climate change and insurance: an evaluation of the Stern report on the economics of climate change, Institute outlook, The Barbon Institute, December 2006.

Guesnerie, R. : Commentaires sur le rapport Stern: Quelques mots d'introduction, Revue d'économie politique, 117(4), 457-462, July-August 2007.

Jacoby, H. D. (MIT): Interpreting the Stern Review on the Economics of Climate Change - Testimony to the Energy Committee, United States Senate, 13 February 2007.

Lawson, D.: Alarmism based on dubious economics, The Independent, 16 January 2007.

Lomborg, B.: Climate Change - Stern Review: The dodgy numbers behind the latest warming scare, Wall Street Journal, 2 November 2006.

Maddison, D.: Further Comments on the Stern Review, Department of Economics, University of Birmingham, Appendix IV, in Center for Science and Public Policy, A Collection of Reviews on the Stern Report, Vol. II, Washington D.C., February 2007.

Quiggin, J.: Stern and the critics on discounting, University of Queensland, 20 December 2006.

Mendelsohn, R.: A Critique of the Stern Report, Regulation, 42-46, Winter 2006-2007.

Nordhaus, W.: The Stern Review on the Economics of Climate Change, Yale University, 17 November 2006, published as: "A Review of the Stern Review on the Economics of Climate Change", J. Econ. Lit., 45(3), 686-702, September 2007.

Reisman, G.: Britain's Stern Review on Global Warming: It Could Be Environmentalism's Swan Song, www.capitalism.net, 6 November 2006.

Samuelson, R. J.: “The Worst of Both Worlds?", Newsweek, 13 November 2006.

Sterner, T. and Persson, U. M.: An Even Sterner Review, Washington D.C., Resources for the Future, RFF DP 07-37, 2007.

Tol, R. S. J.: Is the uncertainty about climate change too large for expected cost-benefit analysis?, Climatic Change, 56(3), 265289, 2003.

Tol, R. S. J.: The Stern Review of the Economics of Climate Change: a comment, http://www.fnu.zmaw.de/fileadmin/ fnu-files/reports/sternreview.pdf 2 November 2006.

Tol, R. S. J. and Yohe, G. W.: A Review of the Stern Review, World Economics, 7(4), 233-250, 2006.

Varian, H.: Recalculating the Costs of Global climate Change, The New York Times, 14 December 2006.

Weitzman, M. L.: The Stern Review of the Economics of Climate Change, 13 March 2007, published as: A Review of the Stern Review of the Economics of Climate Change, J. Econ. Lit., 45(3), 703-724, September 2007a.

Wolf, M.: In spite of economic sceptics, it is worth reducing climate risk, Financial Times, 7 February 2007. 
Yohe, G.: Some thoughts on the damage estimates presented in the Stern Review - A Editorial, The Integrated Assessment Journal, 6(3), 65-72, 2006.
Yohe, G., Tol, R. S. J., Murphy, D.: On Setting Near-term Climate Policy While the Dust Begins to Settle: The Legacy of the Stern Review, Energy \& Environment, 18(5), 621-633, September 2007. 